\title{
Trends in compensation for deaths from occupational cancer in Canada: a descriptive study
}

\author{
Ann Del Bianco PhD, Paul A. Demers PhD
}

Abstract

Background: Occupational cancer is the leading cause of work-related deaths, yet it is often unrecognized and under reported, and associated claims for compensation go unfiled. We sought to examine trends in deaths from occupational cancer, high-risk industries and exposures, and commonly compensated categories of occupational cancers. In addition, we compared deaths from occupational lung cancer for which compensation had been given with total deaths from lung cancer.

Methods: We used data from the Association of Workers' Compensation Boards of Canada pertaining to the nature and source of the injury or disease and the industry in which it occurred (by jurisdiction) to describe trends in compensated claims for deaths from occupational cancer in Canada for the period 1997-2010. We used data published by the Canadian Cancer Society in Canadian Cancer Statistics to compare compensated occupational lung cancer deaths with total estimated lung cancer deaths for the period between 2006 and 2010.

Results: Compensated claims for deaths from occupational cancer have increased in recent years and surpassed those for traumatic injuries and disorders in Canada, particularly in Ontario. Between 1997 and 2010, one-half of all compensated deaths from occupational cancer in Canada were from Ontario. High-risk industries for occupational cancer include manufacturing, construction, mining and, more recently, government services. Deaths from lung cancer and mesothelioma comprise most of the compensated claims for deaths from occupational cancer in Ontario and Canada. These diseases are usually the result of asbestos exposure. The burden of other occupational carcinogens is not reflected in claims data.

Interpretation: Although the number of accepted claims for deaths from occupational cancers has increased in recent years, these claims likely only represent a fraction of the true burden of this problem. Increased education of patients, workers at high risk of exposure and health care providers is needed to ensure that people with work-related cancer are identified and file a claim for compensation.

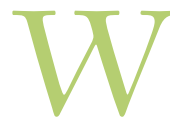

hen most people think about work-related deaths, they envision the tragic fatal injuries that are sometimes reported in the news. In 2006, Sharpe and Hardt wrote a compelling report emphasizing that about 1097 people in Canada were compensated for work-related deaths in 2005 - nearly 5 work-related deaths per day - and that claims for occupational diseases had surpassed those for traumatic injuries and disorders, which had historically accounted for most compensated workplace deaths. ${ }^{1}$ Occupational diseases, such as occupational cancers, receive little public health attention compared with other causes of death. For example, deaths from motor vehicle accidents reached an all-time low in 2009, largely because of the public health prevention strategies that have been implemented over the years. ${ }^{2}$ Increased attention to occupational diseases could thus help leverage prevention efforts.

The main purpose of this study was to examine and better understand recent changes in the patterns of compensated claims for deaths from occupational cancer in Canada. To this end, we examined trends in deaths from occupational cancer, high-risk industries and exposures, and commonly compensated categories of occupational cancers.

\section{Methods}

Workers' compensation is primarily under provincial and territorial jurisdiction in Canada. Workers' compensation boards exist in each province and territory and provide survivor benefits for work-related deaths. Rules vary considerably between jurisdictions. ${ }^{3}$ The only available data source for describing national trends and characteristics of compensated claims for deaths from occupational cancers is the Association of Workers' Compensation Boards of Canada. Although record keeping and reporting vary by jurisdiction, all workers' compensation boards in Canada provide records to this association, which are then converted to a standardized format such that jurisdictional comparisons can be made. Workplace deaths are generally divided into 2 main

Competing interests: None declared.

This article has been peer reviewed.

Correspondence to: Paul A. Demers, paul.demers@ cancercare.on.ca CMAJ Open 2013.DOI:10.9778/cmajo.2013-0015 
categories: deaths attributed to traumatic injuries and disorders, and deaths attributed to occupational diseases. The former category accounts for acute fatal injuries such as burns and amputations, whereas the latter accounts for fatal diseases that may not necessarily result in immediate death, such as cancer.

We requested data for accepted death claims from the Association of Workers' Compensation Boards of Canada. We obtained data pertaining to the nature and source of the injury or disease and the industry in which it occurred by jurisdiction for the period 1997-2010 to conduct descriptive analyses, including time-trend analysis. ${ }^{4}$ Time trends were examined for all deaths from cancer versus those from injuries and disorders. We looked at trends in compensated claims for deaths from occupational cancer by jurisdiction. In addition, we examined accepted claims by industry to determine which industrial sectors had the highest number of compensated claims for deaths from occupational cancer. We investigated occupational cancers in the following categories: mesothelioma, asbestos-related lung cancer, nonasbestos-related lung cancer and all other cancers. We then compared the data on compensated claims for deaths from occupational lung cancer with estimated lung cancer deaths for 2006-2010 published in Canadian Cancer Statistics. ${ }^{5-10}$

\section{Results}

In Canada, compensated claims for deaths from occupational cancer have increased in recent years, surpassing those for traumatic injuries and disorders (Figure 1). Ontario accounted for $52.5 \%-65.0 \%$ of all compensated claims for deaths from occupational cancer in Canada from 1997 to 2010, with the exception of 1998, when Ontario accounted for $46.2 \%$ of Canada's compensated claims (Figure 2). Thus, during the study period, Ontario was the main driving force for national

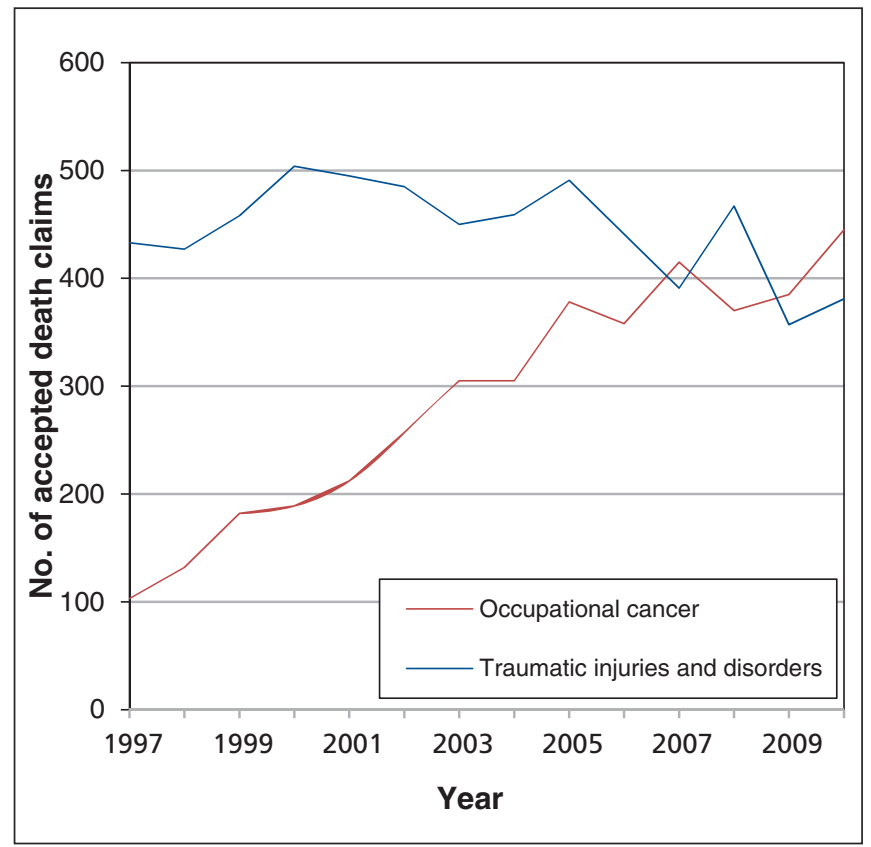

Figure 1: Work-related deaths in Canada for which compensation was received, by year. trends in compensated claims for deaths from occupational cancer. The overall trends seen in Canada were even stronger in Ontario - compensated claims for occupational cancer deaths have been increasing steadily over time, surpassing traumatic injuries and disorders since 2004 (Figure 3).

Both in Ontario and nationwide, the top 3 industries in which claims for deaths from occupational cancer were compensated were manufacturing, construction and mining. However, during the last 5 years of the study period, the number of accepted claims by industry changed, with an increase in the number of claims from workers in government services. This increase has been primarily driven by an increase in the number of claims accepted for firefighters. ${ }^{11,12}$

Between 1997 and 2010, there was a 216.4\% increase in accepted claims for_mesothelioma, a $575.0 \%$ increase in accepted claims for lung cancer and a $512.5 \%$ increase in accepted claims for other cancers (Figure 4) in Canada. During the same period in Ontario, increases were seen for compensated claims for both mesothelioma and lung cancer. In addition, compensated claims for deaths from lung cancer occasionally exceeded those for mesothelioma in Ontario - a phenomenon not seen in the overall Canadian trends, where the number of accepted claims for mesothelioma was consistently higher than those for lung cancer. Ontario underwent a $97.7 \%$ increase in accepted claims for mesothelioma, a $383.3 \%$ increase in accepted claims for lung cancer and a $1300.0 \%$ increase in accepted claims for other cancers during the study period (Figure 5).

From 1997 to 2010, about 70.8\% of accepted occupational cancer death claims in Canada involved exposure to asbestos; a similar percentage was seen within the same period in Ontario (70.6\%). Over time, claims for mesothelioma and lung cancer (combined) accounted for up to $98.4 \%$ of all compensated claims for deaths from occupational cancer in Ontario and up to $87.3 \%$ of such claims in Canada. In the final 5 years of the study period, about $93.0 \%$ of all claims for asbestos-related deaths in Canada that resulted in compensation were attributed to mesothelioma or lung cancer; the corresponding proportion for such claims in Ontario during the same period was $88.7 \%$. As of 2010 , claims for asbestos-related lung cancer accounted for about $69.6 \%$ of compensated lung cancer deaths in Canada and about $73.6 \%$ of such deaths in Ontario.

Between 2006 and 2010, 402 claims for occupational lung cancer deaths were accepted in Ontario alone, whereas 626 were accepted in all of Canada. Statistics Canada ${ }^{5-9}$ has estimated that there were 33400 deaths from lung cancer during the same period in Ontario, and 100600 such deaths across Canada. Thus, $1.2 \%$ of lung cancers in Ontario and $0.6 \%$ of lung cancers in Canada were occupational cancers causing death for which claims resulted in compensation.

\section{Interpretation}

The increasing trends we saw for compensated occupational death claims in Canada are similar to those that have been reported previously. ${ }^{1}$ The number of accepted claims for cancer has steadily risen. The pattern in Ontario is even more striking, with cancers far surpassing traumatic injuries in more recent 
years (Figure 3). These trends could have several explanations. For example, certain differences exist in compensation policies between Ontario and the other provinces and territories. In addition, increased awareness and media attention within specific workplaces can result in an increase in the number of claims submitted and compensated, particularly if stakeholder involvement helps drive such efforts. An example of this phenomenon occurred in Sarnia, Ontario, when many former employees of the Holmes Foundry (or families on behalf of a deceased former employee) applied for and received compensation for occupational cancers up to several decades after diagnosis or, in some cases, death (even after death, some benefits may be available for family members). ${ }^{11,12}$ These occupational cancers would have otherwise gone unrecognized, and claims for compensation may never have been filed.

Nationally, the number of traumatic injury deaths remained somewhat stable over the study period, although there was some evidence of a possible decline in recent years. We saw a decrease in the number of accepted claims for deaths from traumatic injuries and disorders in Ontario. Factors that may account for this trend include changes in the demographic composition of the workforce, shifts in the distribution of employment between industrial sectors, deindustrialization, business cycle effects, structural changes within industries, changes in government regulatory practices, improvements in safety management and increased prevention efforts and strategies. ${ }^{13-16}$

CAREX Canada estimates that most of the workers exposed to asbestos in Canada today are in construction-related industries, with about $88 \%$ of all workers exposed to asbestos employed in specialty trades and building construction. ${ }^{17}$ Previous research confirms that, in Ontario, construction, manufacturing, mining and government services are the industries in which most compensated claims for deaths have occurred. ${ }^{18}$ The increasing number of deaths from occupational cancers receiving compensation in government services is thought to be the result of changes in compensation for firefighters - in Ontario, these changes were prompted by Bill 221 and its amendments. ${ }^{19}$ This legislation ensured that volunteer, part-time and full-time firefighters, as well as fire investigators, would be compensated for a wide range of work-related cancers, which subsequently led to a surge in claims. As a result, over the past 5 years, the government services industry has replaced the mining industry as the third-

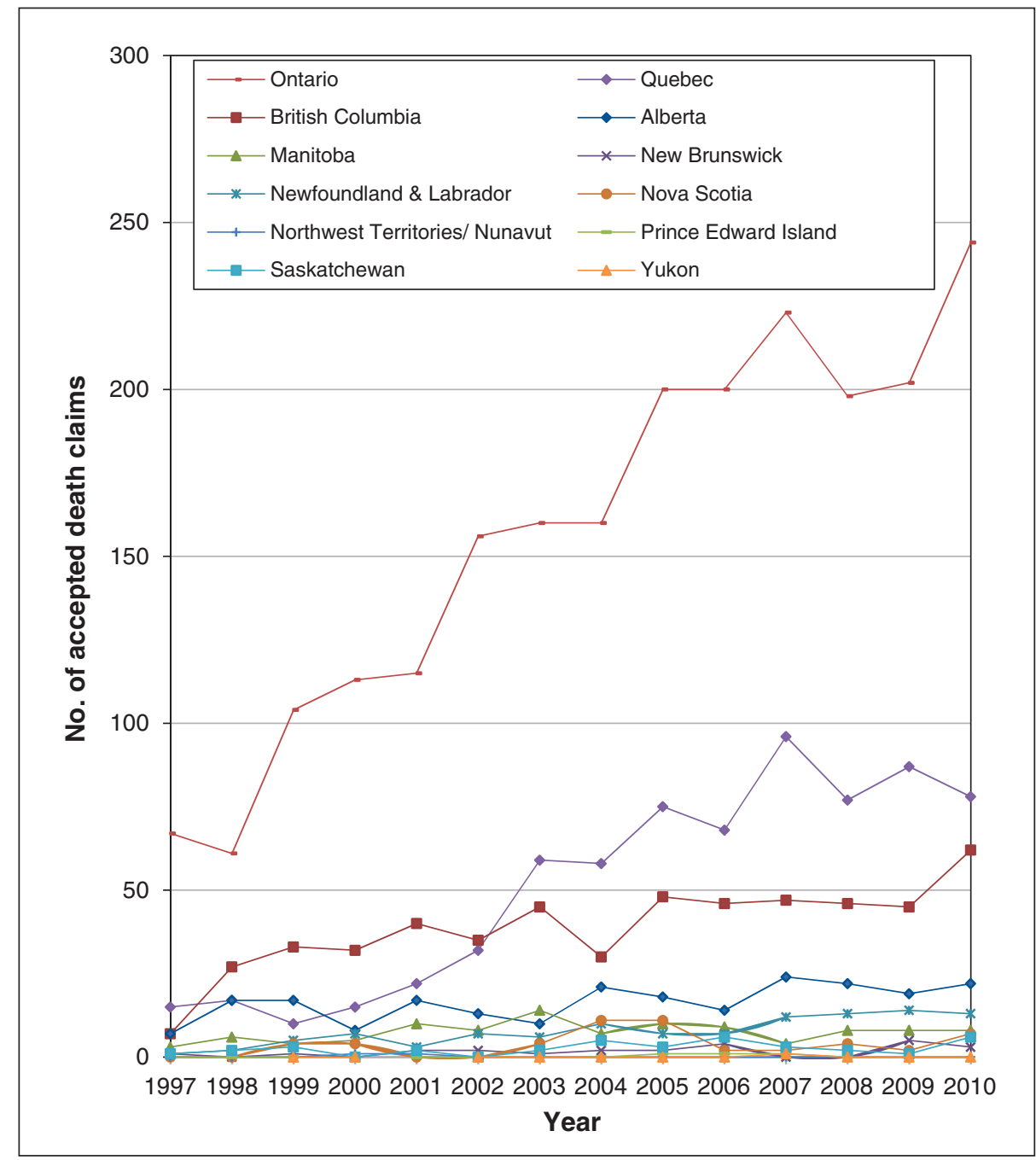

Figure 2: Cases of occupational cancer for which compensation was received, by jurisdiction and year. 
highest industry in terms of compensation for deaths from a wide range of occupational cancers. The 2 leading industries, manufacturing and construction, have predominantly compensated claims for deaths from lung cancer and mesothelioma - deaths that are usually attributed to a history of asbestos exposure.

Since $1996,70 \%$ of the increase in accepted claims for work-related deaths in Canada was attributable to deaths resulting from asbestos exposure. ${ }^{1}$ A common misconception exists that asbestos has been banned from all products or processes recently used or applied in workplaces, which is not necessarily the case. ${ }^{20,21}$ Although asbestos is no longer used in insulation, it still exists in building structures, and some asbestos-containing products, such as brake pads, are still in use. The widespread use of asbestos has substantially decreased over time, and safety measures have been implemented, but workers today are still at risk of asbestos exposure and its associated occupational diseases during building renovations, maintenance and demolition. ${ }^{1,22}$

Exposure to asbestos has been a widespread concern for decades; however, it appears to no longer be on the radar of public health as a result of recent closures of the last remaining asbestos mines in Canada. ${ }^{23}$ Nevertheless, occupational cancer may surface as many as 40 years postexposure and, once the disease process has begun, people no longer exposed continue to be at risk. ${ }^{24,25}$ Most of the compensated claims for deaths from occupational cancer and the increased incidence of mesothelioma have been attributed to past asbestos exposure. ${ }^{24}$ However, many other exposures to carcinogens in workplaces occur that are not captured in claims statistics; for example, exposures to benzene, polycyclic aromatic hydrocarbons, formaldehyde, diesel exhaust, wood dust and radon have all been shown to be associated with occupational cancers. ${ }^{26-28}$

Aronson and colleagues ${ }^{29}$ have suggested that advances in understanding occupational hazards have been motivated by

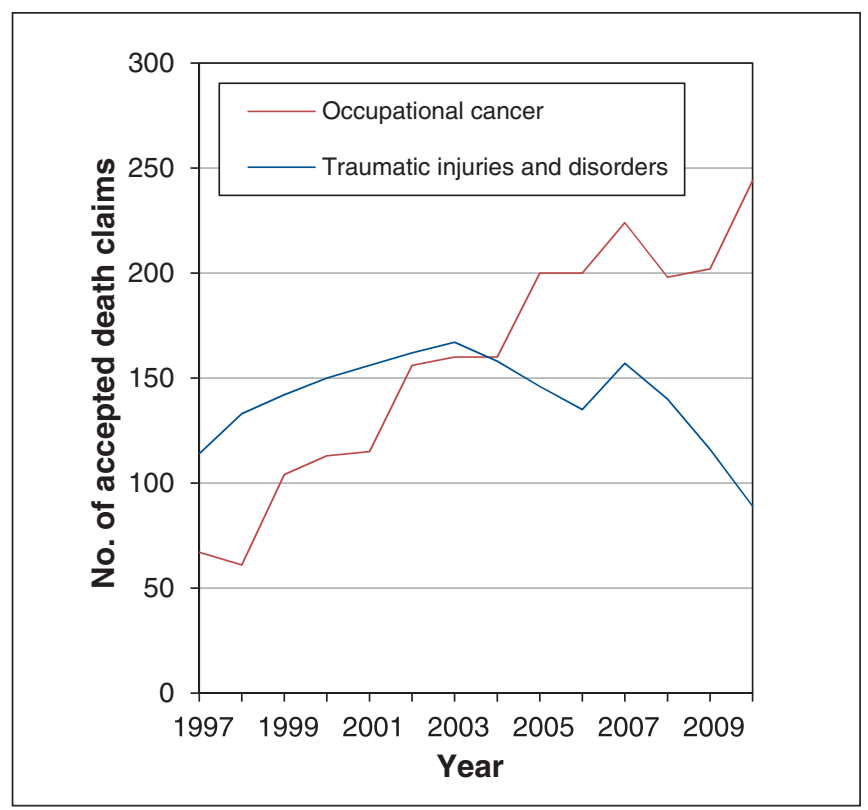

Figure 3: Work-related deaths in Ontario for which compensation was received, by year. anecdotal reports of workers at extreme risk, but many occupational hazards remain undetected. For this reason, the importance of occupational surveillance (i.e., the systematic collection, evaluation and dissemination of data relating to workplace exposures, occupational disease and worker mortality) and the subsequent reporting of results across Canada has been highlighted in several reports. . $^{18,24,29-32}$ Surveillance used to estimate cancers and other diseases attributable to occupational exposures can signal an excess of a particular disease in an unexpected population defined by a common occupation or industry. ${ }^{29,33,34}$

Cancer is known for its many causes and long latency period, and these characteristics pose serious challenges for people who seek compensation for an occupationally induced cancer. Occupational cancer is often unrecognized and underreported, claims for compensation go unfiled, and accepted claims represent only a small proportion of the overall burden. Efforts have been launched in a number of countries to estimate the true burden of occupational cancer. ${ }^{35-39}$ The most extensive of these efforts was in the United Kingdom, where active occupational disease surveillance schemes involve primary care physicians. ${ }^{40}$ Using estimates of the burden of occupational cancers from the UK and the United States, lung cancer accounts for $8 \%-21.1 \%$ of occupational cancers among men and $2 \%-5.3 \%$ of occupational cancers among women. ${ }^{35,36}$

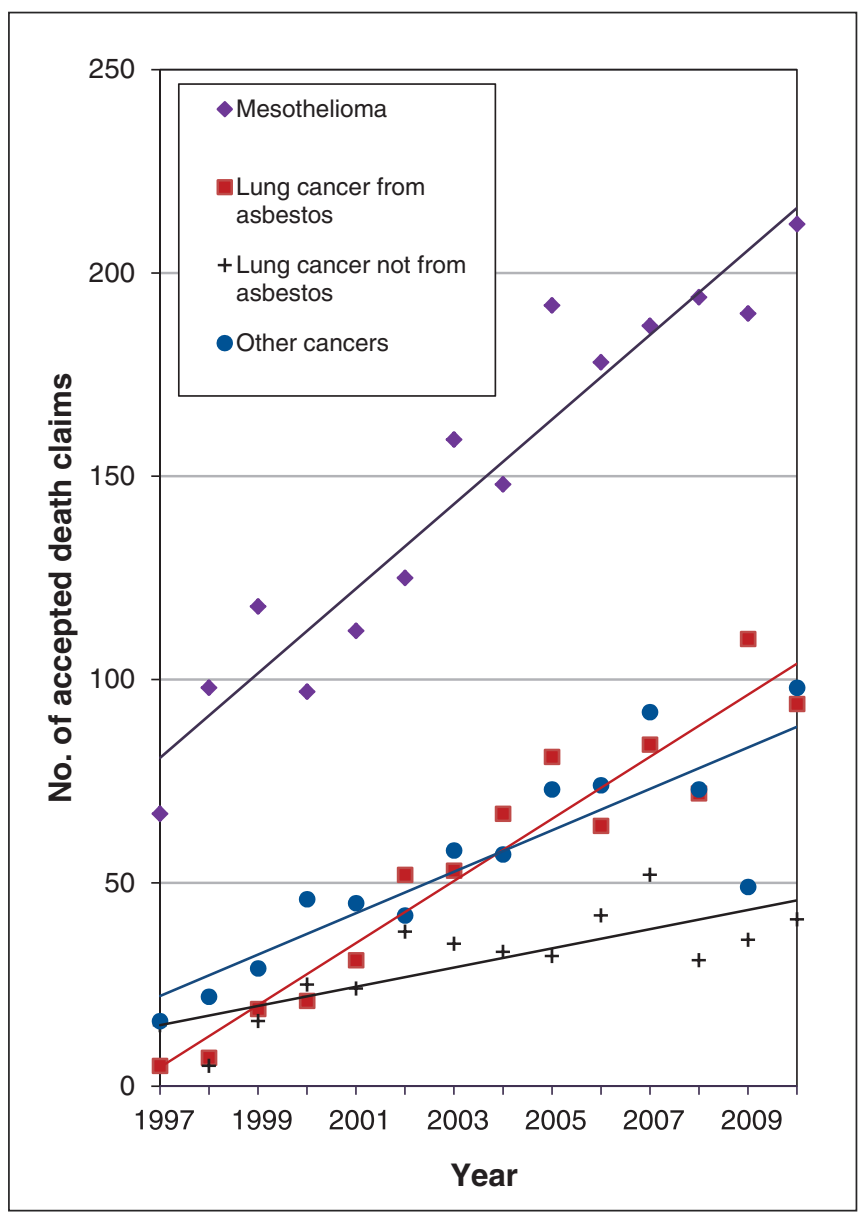

Figure 4: Types of occupational cancer for which compensation was issued in Canada, by year. 
These estimates suggest that comparing compensated claims for lung cancer to total estimated deaths from lung cancer results in an under representation of the burden of occupational cancer. To date, little attempt has been made to estimate the total number of work-related cancers in Canada. Some attempts have been made to summarize the existing literature ${ }^{41}$ and to provide an estimate of the burden of disease; ${ }^{42}$ however, unlike the UK and the US, Canada does not yet have a context-specific percentage that it can use to predict the burden of occupational cancer.

\section{Limitations}

Differences in the number of accepted death claims by jurisdiction exist owing to variations in policies and legislation. ${ }^{3,43-46}$ Employment levels for some industries may differ by region, affecting the number of claims submitted within those jurisdictions. ${ }^{43}$ Furthermore, variations in processing times can affect the number of accepted claims reported in any given year; thus, the data reported do not necessarily represent the year in which the death occurred, but rather the year in which the claim was accepted. ${ }^{43}$

Available data for each of the jurisdictions do not necessarily capture the entire workforce for any given year. For example, data from Ontario in 2010 represented about $71.3 \%$ of the province's workforce, whereas data from Quebec represented about $93.0 \%$ of its workforce for the same year. ${ }^{45}$ Self-employed workers, employees of small businesses, military personnel and other people who are not covered by provincial workers' compensation boards are not represented in claims data. When comparing data from the Association of Workers' Compensation Boards of Canada directly with jurisdictional data, discrepancies may occur, but overall patterns are generally the same. These limitations are unlikely to affect the overall trends we saw over time among the provinces and territories.

\section{Conclusion}

The number of compensated claims for occupational cancer deaths has risen sharply since 1997 and has now surpassed those for traumatic injuries causing death in the workplace. This trend is most notable in Ontario, where there are now more than 2 occupational cancer deaths for each traumatic injury death. However, these claims likely represent only a fraction of the true burden. The Occupational Cancer Research Centre is currently conducting research that will enable researchers to calculate the burden of occupational cancer across Canada and is working to raise awareness among health care providers and the broader community regarding the impact of carcinogens in the workplace.

Physicians can play a key role in identifying individual cases and assisting their patients with compensation by being aware of their patients' hazardous exposures and being vigi-

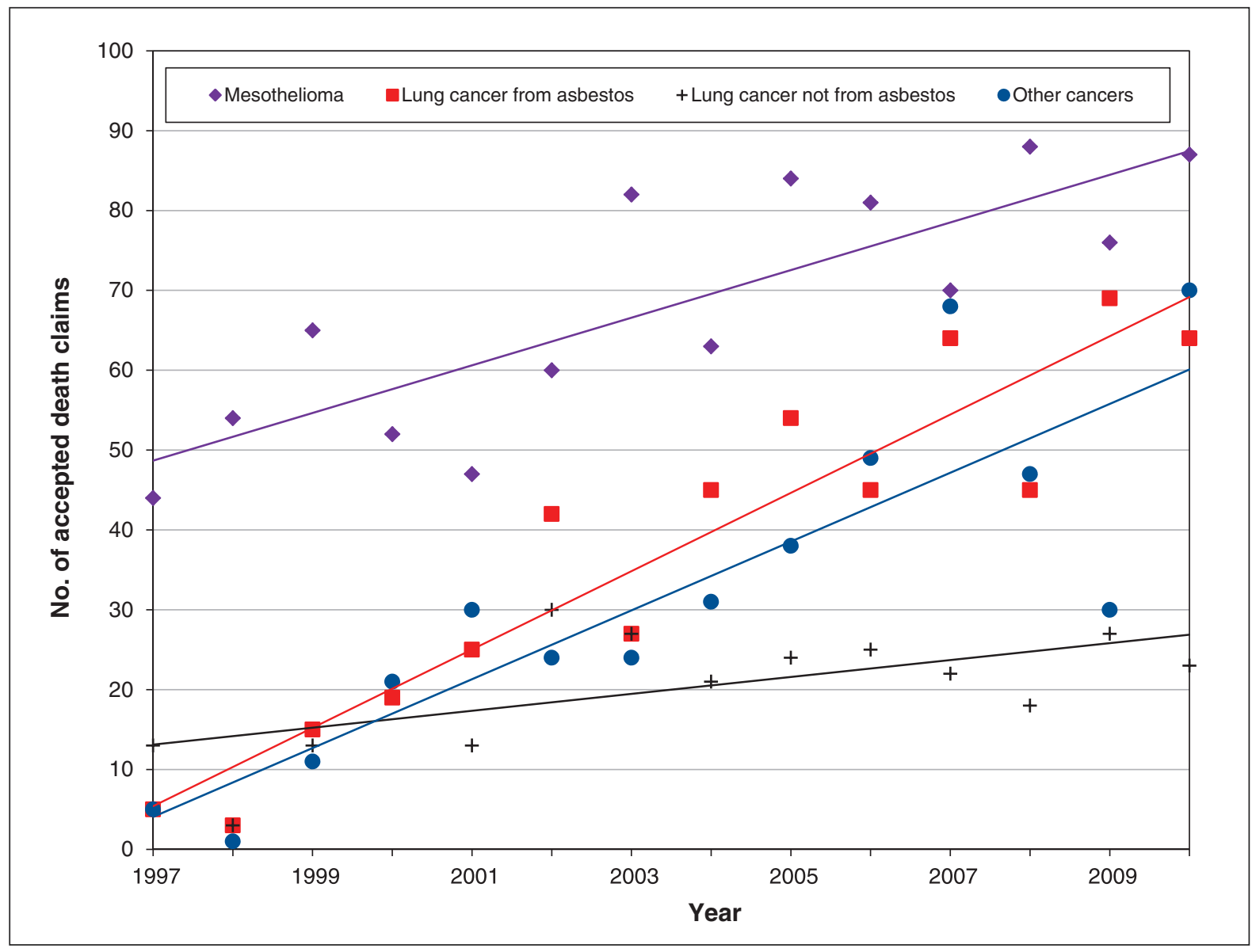

Figure 5: Types of occupational cancer for which compensation was issued in Ontario, by year. 
lant for early signs of work-related disease. By adopting a model in which physicians are more involved with the active surveillance of occupational cancers, and in which the current and projected burden of occupational cancer has been more systematically assessed, Canada can be in a position where efforts are aimed at eliminating or minimizing occupational exposures and preventing these cancers from occurring.

Although the number of accepted claims for deaths from occupational cancers has increased in recent years, these claims still only represent a fractionof the true burden of this problem. Increased education of patients, workers at high risk of exposure and health care providers is needed to ensure that people with work-related cancer are identified and file a claim for compensation.

\section{References}

1. Sharpe, A, Hardt, J. Five deaths a day: workplace fatalities in Canada, 1993-2005. Ottawa (ON): Centre for the Study of Living Standards; 2006.

2. Ontario road safety annual report 2009. Toronto (ON): Ontario Ministry of Transportation; 2009.

3. Lippel, K. Workers' Compensation for asbestos related disease in five Canadian provinces. Occupational Health Clinics for Ontario Workers and Canadian Partnership Against Cancer; 2010.

4. National Work Injury Statistics Program (NWISP), 1997-2010 data years. Toronto (ON): Association of Workers' Compensation Boards of Canada (AWCBC)

5. Canadian cancer statistics 2006. Toronto (ON): Canadian Cancer Society/National Cancer Institute of Canada; 2006.

6. Canadian cancer statistics 2007. Toronto (ON): Canadian Cancer Society/National Cancer Institute of Canada; 2007.

7. Canadian cancer statistics 2008. Toronto (ON): Canadian Cancer Society/National Cancer Institute of Canada; 2008.

8. Canadian cancer statistics 2009. Toronto (ON): Canadian Cancer Society/National Cancer Institute of Canada; 2009.

9. Canadian Cancer Society's Steering Committee. Canadian cancer statistics 2010: Special topic: end-of-life care. Toronto (ON): Canadian Cancer Society; 2010.

10. Canadian Cancer Society's Steering Committee. Canadian cancer statistics 2011: featuring colorectal cancer. Toronto (ON): Canadian Cancer Society; 2011.

11. Brophy J, Parent M-É. Documenting the asbestos story in Sarnia. New Solut 1999;9:297-316.

12. Keith MM, Brophy JT. Participatory mapping of occupational hazards and disease among asbestos-exposed workers from a foundry and insulation complex in Canada. Int 7 Occup Environ Health 2004;10:144-53.

13. Breslin FC, Tompa E, Mustard C, et al. Association between the decline in Workers' Compensation claims and workforce composition and job characteristics in Ontario, Canada. Am 7 Public Health 2007;97:453-5.

14. Mustard C, Cole D, Shannon H, et al. Declining trends in work-related morbidity and disability, 1993-1998: a comparison of survey estimates and compensation insurance claims. Am 7 Public Health 2003;93:1283-6.

15. Road to zero: a prevention strategy for workplace health and safety in Ontario2008_ 2012. Toronto (ON): Workplace Safety and Insurance Board (WSIB); 2008.

16. Loomis D, Richardson DB, Bena JF, et al. Deindustrialisation and the longterm decline in fatal occupational injuries. Occup Environ Med 2004;61:616-21.

17. Occupational exposure estimates: asbestos. Vancouver (BC): Carex Canada; 2012. Available: www.carexcanada.ca/en/asbestos/occupational_exposure_estimates /phase_2/ (accessed 2012 Feb. 13).

18. Pichora EC, Payne JI. Trends and characteristics of compensated occupational cancer in Ontario, Canada, 1937-2003. Am f Ind Med 2007;50:980-91.

19. Ontario. "An Act to amend the Workplace Safety and Insurance Act, 1997 with respect to firefighters and certain related occupations." Bill 221. 38th Legislature, 1st Session, 2007. Toronto (ON): Legislative Assembly, 2007. (Assented to May 4, 2007.)

20. Bridge, S. Asbestos in brakes: one community's struggle. Toronto (ON): Canadian Broadcasting Corporation; 2012 Mar 21. Available: www.cbc.ca/news/canada /story/2012/03/20/f-asbestos-tilbury-workers.html (accessed 2013 Jun. 20).

21. Bridge, S. Asbestos brake pad ban proposed. Toronto (ON): Canadian Broadcasting Corporation; 2012 Mar 21. Available: www.cbc.ca/news/canada/story /2012/03/20/asbestos-brake-ban-proposal-ontario.html (accessed 2013 Jun. 20).

22. Marrett LD, Ellison LF, Dryer D. Canadian cancer statistics at a glance: mesothelioma. CMA7 2008;178:677-8.

23. Hiltz R. Pro-asbestos advocacy group shuts its doors. The Montreal Gazette. 2012 Apr. 30.

24. Kirkham TL, Koehoorn MW, McLeod CB, et al. Surveillance of mesothelioma and workers' compensation in British Columbia, Canada. Occup Environ Med 2011; 68:30-5.
25. Driscoll, T, Steenland, K, Pruss-Ustun, A, et al. Occupational carcinogens: assessing the environmental burden of disease at national and local levels. Geneva (Switzerland): World Health Organization; 2004.

26. Cancer risk factors in Ontario: evidence summary. Toronto (ON): Cancer Care Ontario; 2013.

27. Baan R, Grosse Y, Straif K, et al.; WHO International Agency for Research on Cancer Monograph Working Group. A review of human carcinogens - part F: chemical agents and related occupations. Lancet Oncol 2009;10:1143-4.

28. Straif K, Benbrahim-Tallaa L, Baan R, et al.; WHO International Agency for Research on Cancer Monograph Working Group. A review of human carcinogens - part C: metals, arsenic, dusts, and fibres. Lancet Oncol 2009;10:453-4.

29. Aronson KJ, Howe GR, Carpenter M, et al. Surveillance of potential associations between occupations and causes of death in Canada, 1965-91. Occup Environ Med 1999;56:265-9.

30. Payne JI, Pichora E. Filing for workers' compensation among Ontario cases of mesothelioma. Can Respir 7 2009;16:148-52.

31. Cree MW, Lalji M, Jiang B, et al. Under-reporting of compensable mesothelioma in Alberta. Am 7 Ind Med 2009;52:526-33

32. Teschke K, Morgan MS, Checkoway H, et al. Mesothelioma surveillance to local sources of exposure to asbestos. Can F Public Health 1997;88:163-8.

33. Beach J, Burstyn I, Cherry N. Estimating the extent and distribution of newonset adult asthma in British Columbia using frequentist and bayesian approaches. Ann Occup Hyg 2012;56:719-27.

34. Cherry N, Beach J, Burstyn I, et al. Data linkage to estimate the extent and distribution of occupational disease: new onset adult asthma in Alberta, Canada. Am f Ind Med 2009;52:831-40.

35. Steenland K, Burnett C, Lalich N, et al. Dying for work: the magnitude of US mortality from selected causes of death associated with occupation. Am 7 Ind Med 2003;43:461-82.

36. Rushton L, Bagga S, Bevan R, et al. Occupation and cancer in Britain. Br 7 Cancer 2010;102:1428-37.

37. Nurminen M, Karjalainen A. Epidemiologic estimate of the proportion of fatalities related to occupational factors in Finland. Scand 7 Work Environ Health 2001;27:161-213.

38. Driscoll T, Nelson DI, Steenland K, et al. The global burden of disease due to occupational carcinogens. Am 7 Ind Med 2005;48:419-31.

39. t' Mannetje A, Pearce N. Quantitative estimates of work-related death, disease and injury in New Zealand. Sand 7 Work Environ Health 2005;31:266-76.

40. Meyer JD, Holt DL, Chen Y, et al. SWORD '99: surveillance of work-related and occupational respiratory disease in the UK. Occup Med (Lond) 2001;51:204-8.

41. The burden of occupational cancer. Toronto (ON): Occupational Cancer Research Centre; 2011.

42. Orenstein, MR, Dall, T, Curley, $\mathrm{P}$, et al. The economic burden of occupational cancers in Alberta. Calgary (AB): Alberta Health Services, Health Protection, Environment Unit; 2010.

43. National Work Injury and Disease Statistics Program (NWISP) data definitions and considerations. Toronto (ON): Association of Workers Compensation Boards of Canada; 2011. Available: www.awcbc.org/common/assets/english\%20pdf /2010_nwisp_definitions\&considerations.pdf (accessed 2013 Jun. 20).

44. Preface to accompany NWISP statistics - data year 2009. Toronto (ON): Association of Workers' Compensation Boards of Canada; 2011. Available: www.awcbc .org/common/assets/english\%20pdf/2010_nwisp_preface_report.pdf (accessed 2013 Jun. 20)

45. Scope of coverage - industries/occupations. Toronto (ON): Association of Workers' Compensation Boards of Canada; 2012. Available: www.awcbc.org/common /assets/assessment/industries_occupations_covered.pdf (accessed 2013 Jan. 31).

46. Occupational (industrial) disease - definitions, policy, schedules, regulation and legislation Toronto (ON): Association of Workers' Compensation Boards of Canada; 2012. Available: www.awcbc.org/common/assets/legislation/occupational_disease.pdf (accessed 2013 Jun. 20)

Affiliations: Occupational Cancer Research Centre (Del Bianco, Demers); Faculty of Environmental Studies (Del Bianco), York University; Dalla Lana School of Public Health (Demers), University of Toronto, Toronto, Ont.

Contributors: Ann Del Bianco was responsible for the acquisition of the data and its analysis, and drafting the manuscript. Paul A. Demers conceived the idea for this study. Both authors contributed to the design and interpretation of the study and revised the manuscript for important intellectual content. Both authors approved the final version submitted for publication.

Funding: This study was conducted by the Occupational Cancer Research Centre, which is based in Cancer Care Ontario and is further funded by the Workplace Safety and Insurance Board of Ontario and the Ontario Division of the Canadian Cancer Society.

Supplemental information: For reviewer comments and the original submission of this manuscript, please see www.cmajopen.ca/content /1/3/E91/suppl/DC1 